\title{
STUDY ON UITILIZATION OF MORINGA OLEIFERA AS COAGULATION
}

\author{
Patil G.K ${ }^{1}$, Sadgir P.A ${ }^{2}$ \\ ${ }^{1,2}$ Department of Civil Engineering, Govt. College of Engineering, Aurangabad (M.S.) India \\ gkp13@rediffmail.com
}

\begin{abstract}
In this paper, use of Moringa Oleifera seeds to improve the quality of drinking water was investigated. A study was carried out to know the efficiency of Moringa Oleifera seed suspension for removal of turbidity of water. Turbid water sample of low turbidity (50 $\mathrm{mg} / \mathrm{L})$ was prepared in the laboratory using bentonite clay, kaolin clay and black cotton soil. Moringa Oleifera seed suspension was added as coagulant in concentration of 20,40,60, and $80 \mathrm{mg} / \mathrm{L}$ The dosages of Moringa Oleifera seed suspension were 125, 250, 375 and $500 \mathrm{mg} / \mathrm{L}$. Moringa Oleifera seed suspension was found to be effective in treating the water.
\end{abstract}

Keywords: Moringa Oleifera Seed, Turbidity, Hardness and Extraction

$* * *$

\section{INTRODUCTION}

During the treatment of water finely divided silica, clay and organic matter do not settle down easily and hence cannot be removed by simple sedimentation. Such impurities are generally removed by adding certain chemicals, which produce electric charge that neutralizes oppositely charged colloidal particles and bring about their coalescence. Coagulants are widely used for removal of colloidal and suspended materials in the form of turbidity. Aluminum and ferric salts are the mainly used coagulants all over the world for treatment of water. However, their application may have considerable disadvantages, the most important being possible negative effect on consumers' health. Several studies reported that chemical coagulants remain in tap water after coagulation and may induce Alzheimer's disease. On the other hand, sludge disposal to the environment is of concern. That is why considerable attention is focused on the development of new coagulants, preferably from natural and renewable sources, which have to be safe for human health as well as biodegradable.

Moringa Oleifera is a multipurpose tree that grows widely throughout the tropics. In addition to use as coagulant, Moringa Oleifera can also be used for removal of hardness of water. This paper evaluates the use of Moringa Oleifera seeds suspension as coagulants as well as for removal of hardness of water and reports an economical and environmentally safe method of water purification. This will show the way to improve the quality of drinking water in the rural areas.

\subsection{Literature Review}

Francis K. Amaglaoh et. al. (2009) investigated the use of Moringa Oleifera seeds as coagulant for water purification.
Tests were carried out using with a dosage of 4, 6, 8, 10 and $12 \mathrm{~g} / \mathrm{L}$ of powder Moringa Oleifera seeds as coagulant. The 12 $\mathrm{g} / \mathrm{L}$ treatment gave values that are acceptable according to the WHO guidelines for safe drinking water. The MPN per 100 $\mathrm{ml}$ for total coliform counts had values from 2 to 17 . A study carried out by Abaliwano J K et. al.(2008) showed the effectiveness of Moringa Oleifera for turbidity removal of up to $97 \%$ for high turbid water and $86 \%$ for low turbid water. The effect of mixing intensity and time was also investigated and slow mixing time found to have the highest effect on the treated water quality with higher removal of turbidity. S. Katayon (2006) tested Moringa Oleifera as primary coagulant in high rate settling pilot scale water treatment plant. The coagulation efficiency of crushed seed kernels from Moringa Oleifera was examined using high rate settling module pilot plant. The seeds of Moringa Oleifera have shown promise as a coagulant for water treatment. The turbidity after filtration was well below 5 NTU from the synthetic turbid water of 200 NTU. Raveendra Babu and Malay Chaudhari (2005) carried out laboratory tests to ascertain the use of M. Oleifera as coagulant to clarify turbid water. They found that direct filtration of turbid surface water (turbidity 15-25 NTU) with seeds of Moringa Oleifera produced a substantial improvement in its aesthetic and microbiological qualities. Sani (1990) and Fahmi et al., (2011) observed that in addition to turbidity removal, the hardness was also removed after coagulation with Moringa Oleifera and settling. Muyibi and Evson (1996) reported that Moringa Oleifera which was extracted with distilled water can be used to remove hardness from synthetic hard water, naturally surface hard water and tube well water. Muyibi and Evson (1996) reported that higher dosages were required to achieve equivalent residual hardness for water samples with same initial hardness but higher number of hardness causing species in the water. 


\subsection{Objective}

The objective of this study was to carry out investigation into the processes involved in coagulation of water using dry Moringa Oleifera seed suspension.

\section{MATERIALS AND METHODS}

\subsection{Water Sources}

10 grams of bentonite, kaolin and black cotton soil were added in $500 \mathrm{ml}$ of water and were allowed to soak for 24 hours. This was used as stock solution of $10000 \mathrm{mg} / \mathrm{L}$ concentration. The stock solution was diluted to prepare water sample of 50 NTU turbidity.

\subsection{Preparation of Moringa Oleifera Seed Suspension}

The Moringa Oleifera used in this study was obtained from Aurangabad city. The seed wings and coat from selected good quality Moringa Oleifera seeds were removed and the kernel ground to fine powder in a domestic food blender. 2 grams of Moringa Oleifera seed powder was added in $200 \mathrm{ml}$ of distilled water and the mixture was blended in high speed mixer for 30 second. The suspension so obtained was filtered through muslin cloth to give a stock solution of $10 \mathrm{~g} / \mathrm{L}$. Each time fresh solution was prepared for the experimental work.

\subsection{Experimental Set Up:}

For finding out efficiency of turbidity removal, $500 \mathrm{ml}$ of water sample was poured in four beaker of $1 \mathrm{~L}$ capacity. Moringa Oleifera seed suspension was added as coagulant in concentration of 20,40,60, and $80 \mathrm{mg} / \mathrm{L}$. The paddles of jar test apparatus were put in the beaker. The paddles were rotated at fast speed for $1 \mathrm{~min}$ so as to thoroughly mix the coagulant. Slow mixing was carried out for $15 \mathrm{~min}$ so as to bring coagulant and colloidal particles in intimate contact and form a floc. Settlement period of 15 min was allowed so as to settle down the floc. The residual turbidity was measured after 15 min of settlement.

\section{RESULTS AND DISCUSSION}

Bentonite clay, kaolin and black cotton soil was used for preparing turbid water of 50 NTU. Moringa Oleifera seed suspension was added in concentration of 20, 40, 60 and 80 $\mathrm{mg} / \mathrm{L}$. The turbidity of water sample was reduced to $3.4 \mathrm{NTU}$ for a dose of $50 \mathrm{mg} / \mathrm{L}$ using alum as coagulant for bentonite clay. The turbidity of water was reduced to $0.2 \mathrm{NTU}$ for Moringa Oleifera seed suspension as coagulant for bentonite clay. In case of kaolin, the turbidity was reduced to $5.1 \mathrm{NTU}$ using $80 \mathrm{mg} / \mathrm{L}$ of alum dose. Abnormal behavior was observed for Moringa Oleifera as coagulant for kaolin. Turbidity was reduced to $\quad 2.5 \mathrm{mg} / \mathrm{L}$ of alum dose for black cotton soil. Reduction of turbidity to $1.3 \mathrm{NTU}$ was observed using $60 \mathrm{mg} / \mathrm{L}$ dose of Moringa Oleifera for black cotton soil.
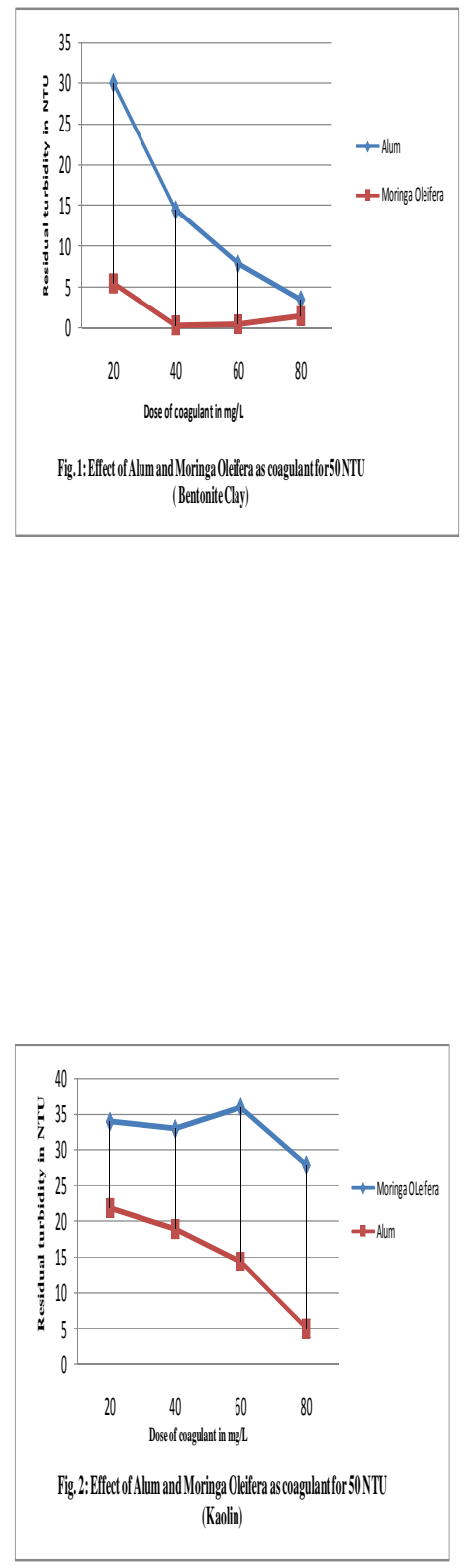

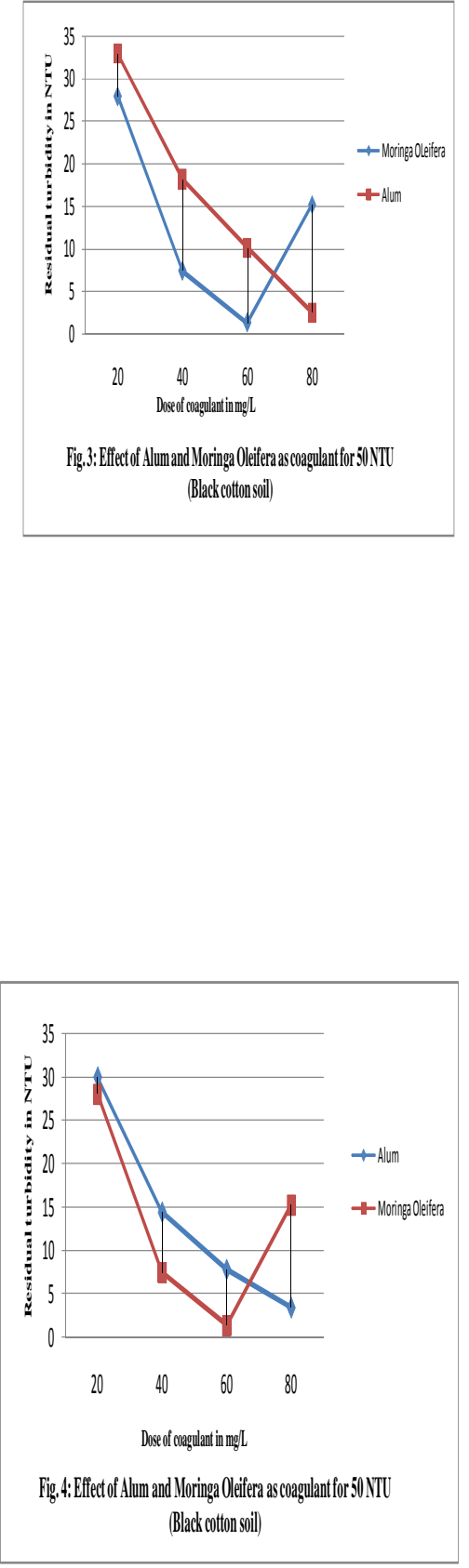

\section{CONCLUSIONS}

Moringa Oleifera is a natural product, and the chemical constituent and structure is not fully known. The interaction of the seed with chemical and other substances in raw water are also not fully understood and the products of interaction are not all known. Further studies would therefore have to be carried out to provide insight into the interaction between Moringa Oleifera seed suspension and the constituents of raw water, and the product of the interactions. It is recommended that efforts be made to carry out further studies at pilot plant level to provide the necessary data for field applications.

1. Moringa Oleifera could be successively used as coagulant in different types of turbidities.

2. Moringa Oleifera has potential to be used in the treatment of waters for domestic use particularly in villages.

\section{REFERENCES}

[1] APHA, Standards Methods for the Examination of Water and Wastewater, $7^{\text {th }}$ edn. American Public Health Association, San Francisco, 1992.

[2] Fahmi, Muhammad Ridwan., Nor Wahidatul Azura Zainon Najib, Pang Chan Ping and Nasrul Hamidin, "Mechanism of Turbidity and Hardness removal in hard water sources by using Moringa Oleifera", Journal of Applied Sciences, 1: 1-7, 2011.

[3] Francis Kweku Amagloh and Amos Benang, "Effectiveness of M. Oleifera seeds as Coagulant for Water Purification", African Journal of Agricultural Research, 4 (1): 119-123, 2009.

[4] Muyibi, Suleyman A and Lilian M. Evison, “ Moringa Oleifera Seeds for Softening Hardwater", Journal of Water Research, 29 (4):1099-1105, 1995.

[5] Muyibi, Suleyman A and Lilian M. Evison, "Coagulation of turbid water and softening of hard water with Moringa Oleifera seeds", International Journal of Environmental Studies, 49: 247-259, 1996.

[6] Sani M. A. "The use of Zogale seeds for water treatment", B. Eng., Bayero University, Kano, Nigeria, 1990. 